УДК 621.365.46:630 $\quad$ व 892:620.91

DOI: 10.36718/1819-4036-2019-11-158-164
И.В. Алтухов, С.М. Быкова,

Г.В. Лукина, С.В. Подъячих, Е.Я. Мучкина

\title{
ПРИМЕНЕНИЕ ВОЗОБНОВЛЯЕМЫХ ИСТОЧНИКОВ ЭНЕРГИИ ДЛЯ ПЕРЕРАБОТКИ И СУШКИ ДИКОРАСТУЩЕГО РАСТИТЕЛЬНОГО СЫРЬЯ
}

\author{
I.V. Altukhov, S.M. Bykova \\ G.V. Lukina, S.V. Podiyachikh, E.Ya. Muchkina
}

\section{RENEWABLE ENERGY APPLICATIONS FOR PROCESSING AND DRYING OF WILD-GROWING VEGETAL RAW MATERIALS}

Алтухов И.В. - д-р техн. наук, проф. каф. энергообеспечения и теплотехники Иркутского государственного аграрного университета им. А.А. Ежевского, Иркутская обл., Иркутский р-н, п. Молодежный.

E-mail: altukhigor@yandex.ru

Быкова С.М. - старший преподаватель каф. энергообеспечения и теплотехники Иркутского государственного аграрного университета им. А.А. Ежевского, Иркутская обл., Иркутский $\mathrm{p}-\mathrm{H}$, п. Молодежный.

E-mail: bickowa.swetlana2011@yandex.ru

Лукина Г.В. - канд. техн. наук, доц. каф. электроснабжения и электротехники Иркутского государственного аграрного университета им. А.А. Ежевского, Иркутская обл., Иркутский р-н, п. Молодежный.

E-mail: lukinagv@yandex.ru

Подъячих C.B. - канд. техн. наук, зав.каф. электроснабжения и электротехники Иркутского государственного аграрного университета им. А.А. Ежевского, Иркутская обл., Иркутский р-н, п. Молодежный.

E-mail: psv78@yandex.ru

Мучкина Е.Я. - д-р биол. наук, проф. каф. экологии и природопользования Института экологии и географии Сибирского федерального университета, г. Красноярск.

E-mail: emuchkina@yandex.ru

Цель исследования - обоснование применимости возобновляемьх источников энергии для технологических процессов сушки и переработки дикорастущего растительного сырья 6 труднодоступных зонах Байкальского региона Иркутской области и получения качественных продуктов высокой пищевой ченности. Для достижения поставленной цели необходимо решить следующие задачи: провести анализ по-
Altukhov I.V. - Dr. Techn. Sci., Prof., Chair of Power Supply and Heating Engineering, Irkutsk State Agrarian University named after A.A. Ezhevsky, Irkutsk Region, Irkutsk District, S. Molodyozhny.

E-mail: altukhigor@yandex.ru

Bykova S.M. - Senior Lecturer, Chair of Power Supply and Heating Engineering, Irkutsk State Agrarian University named after A.A. Ezhevsky, Irkutsk Region, Irkutsk District, S. Molodyozhny.

E-mail: bickowa.swetlana2011@yandex.ru

Lukina G.V. - Cand. Techn. Sci., Assoc. Prof., Chair of Power Supply and Heating Engineering, Irkutsk State Agrarian University named after A.A. Ezhevsky, Irkutsk Region, Irkutsk District, S. Molodyozhny.

E-mail: lukinagv@yandex.ru

Podiyachikh S.V. - Cand. Techn Sci., Head, Chair of Power Supply and Heating Engineering, Irkutsk State Agrarian University named after A.A. Ezhevsky, Irkutsk Region, Irkutsk District, S. Molodyozhny.

E-mail: psv78@yandex.ru

Muchkina E.Ya. - Dr. Biol. Sci., Prof., Chair of Ecology and Environmental Management, Institute of Ecology and Geography, Siberian Federal University, Krasnoyarsk.

E-mail: emuchkina@yandex.ru

тенциала дикорастущего растительного сырья, произрастающего в данном регионе и области; оценить возможность использования различных возобновляемых источников по их эфрфеективности и энергозатратам; определить наиболее подходящие методы сушки; обосновать выбор выпускаемых технических устройств, реализующих предпочтенные методы. Объектами исследования являются возоб- 
новляемые источники энергии и технические системы, способные реализовать эфрфективные методы сушки. Для решения поставленных задач были использованы теоретические методы анализа существующих технических средств возобновляемой энергетики, а также устройств для сушки растительного сырья. Кроме того, использовались статистические методы для оценки показателей дикорастущего растительного сырья и экономического потенциала возобновляемых источников энергии. В резульmame теоретического анализа выяснили, что в Байкальском регионе Иркутской области произрастают более 1733 видов растительного сырья, из которых 224 вида могут использоваться как пищевые. Анализ показьвает, что потенциал возобновляемых источников составляет около 10 тыс. $m$ условного топлива. Разбор технических устройств для сушки дикорастущего растительного сырья показал, что средняя мощность установок «Универсал-СД-4» на 25-30 \% ниже при одинаковых объемах загрузки (30-120 к2) и равной продолжительности сушки. Для обеспечения энергии установок данного тuпа наиболее подходят микроГЭС, так как способны создавать необходимую мощность независимо от погодных условий.

Ключевые слова: переработка, сушка, технология, дикорастущее сырье, возобновляемый источник, энергия.

The purpose of these studies is to justify the applicability of renewable energy sources for technological processes of drying and processing wild-growing vegetable raw materials in hard-to-reach zones of the Baku region of the Irkutsk region and to obtain quality products of high nutritional value. In order to achieve this goal, it was necessary to carry out an analysis of the potential of wild plant raw materials growing in the region and the region; Assess the feasibility of using different renewable sources in terms of their efficiency and energy consumption; Determine the most appropriate drying methods; Justify selection of available technical devices implementing preferred methods. The objects of the study are renewable energy sources and technical systems capable of implementing effective drying methods. Theoretical methods of analysis of existing technical means of renewable energy, as well as devices for drying vegetable raw materials were used to solve the set tasks. In addition, statistical methods were used to assess wild plant raw materials and the economic potential of renewable energy sources. As a result of theoretical analysis, it was found that in the Baku region of the Irkutsk region more than 1733 types of plant raw materials grow, of which 224 types can be used as food. The analysis shows that the potential of renewable sources is about 10 thousand tons of conventional fuel. Analysis of technical devices for drying wild-growing vegetable raw materials showed that the average capacity of "Universal-SD-4" plants is 25-30 \% lower at the same loading volumes (30-120 kg) and equal drying duration. Micro-hydroelectric power plants are the most suitable for the energy of this type of plant, as they are able to create the necessary power regardless of weather conditions.

Keywords: processing, drying, technology, wild raw materials, renewable source, energy.

Введение. Байкальский регион РФ богат возобновляемым растительным сырьем. Проведенный анализ подтверждает, что на рынке Иркутской области претворяются в жизнь более $38,5 \%$ дикоросов, в СФО - 6,5\%, в других регионах РФ 18,5 \% [1]. Заготовкой дикорастущего сырья и его переработкой заняты 23 предприятия в 15 районах области. Возможный сбыт дикоросов на рынке рассматривается как актуальная задача в региональной экономике с целью повышения продовольственной безопасности и уменьшения зависимости от ввоза аналогичного сырья из других регионов. Лесные растения, относящиеся к сосудистым пищевым растениям, включают в себя более 177 видов, в том числе 27 - водно-болотные. При этом объемы использования этих ресурсов весьма незначительны и несопоставимы с масштабами их природного воспроизводства. В лесах Иркутской области произрастает большое количество дикорастущего растительного сырья, пригодного для получения ценных продуктов и продуктов высокой пищевой ценности, которые можно использовать не только для пищевого употребления, но и в качестве лекарственного сырья, диетического питания детей и спортсменов (рис. 1). 


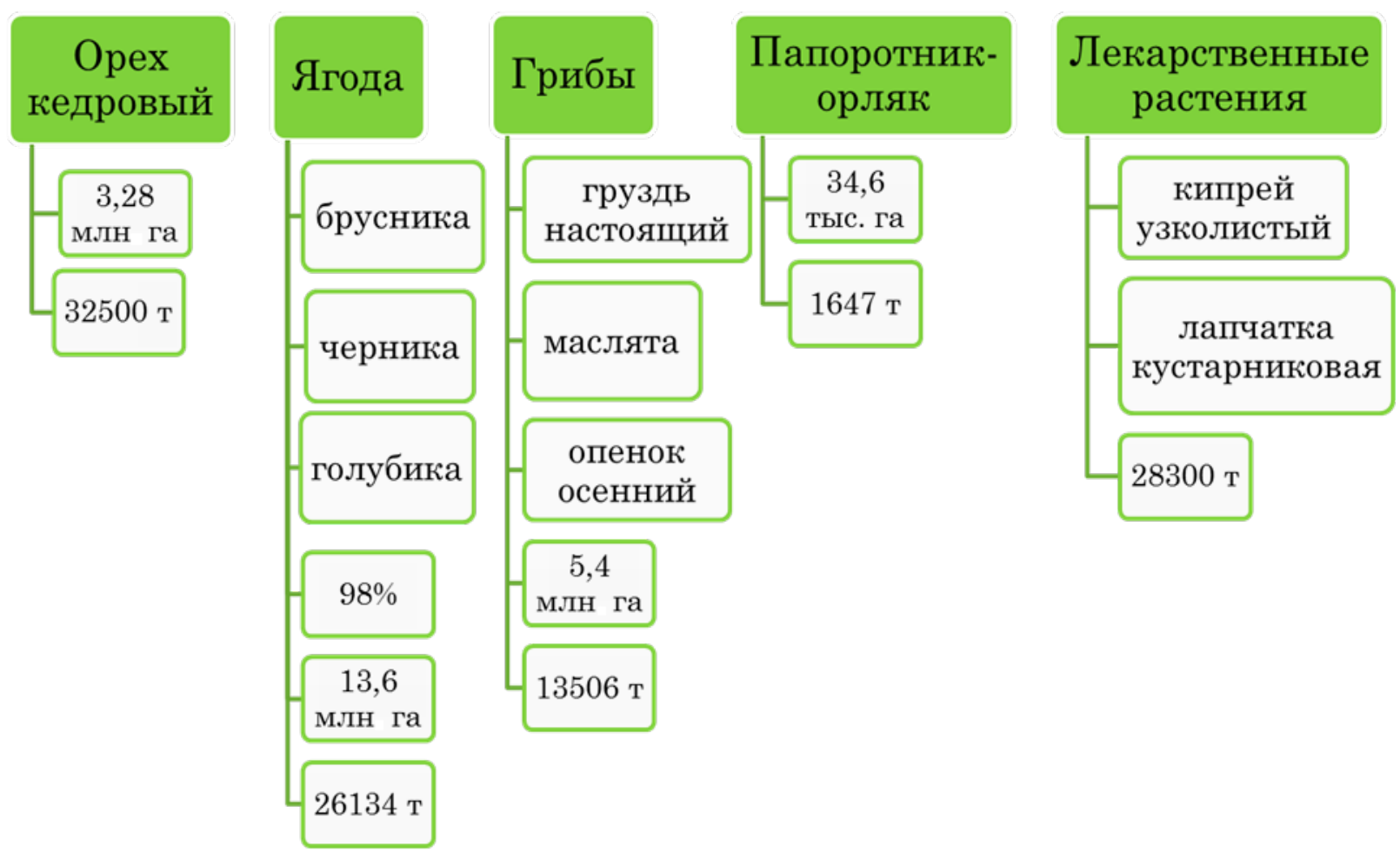

Pис. 1. Выборочная оценка биологической и хозяйственной продуктивности дикорастущих ресурсов в Иркутской области

В дикорастущем сырье содержатся уникальные микроэлементы и витамины, которые могут быть сохранены при правильной технологии переработки и сушки данного сырья.

Задачей получения ценных продуктов из дикорастущего сырья является необходимость организации его переработки и сушки непосредственно на месте сбора или как можно ближе к местам произрастания. Решение данной задачи возможно при использовании возобновляемых источников энергии, оптимальных для данного региона, правильном выборе технологического оборудования и соблюдении правил переработки и сушки.

Большая часть рассматриваемого региона произрастания дикорастущего сырья расположена в зонах, характеризующихся десицитом электроэнергии. При этом ряд территорий, возможных для развития переработки дикорастущего сырья, вообще не имеет централизованных систем электроснабжения. В этой ситуации вопрос активного использования возобновляемых источников энергии (ВИЭ) для выработки электрической и тепловой энергии становится актуальным, что также позволяет уменьшить негативное воздействие на окружающую среду. По- этому необходимость применения возобновляемых источников энергии в удаленных зонах очевидна, и именно этим энергетическим установкам с экологически чистой составляющей необходимо уделять существенное внимание [2].

Интенсивность солнечного излучения на территории Иркутской области и Байкальского региона составляет более 2400 ч/год с доминированием прямой радиации. Средний показатель суммарной дневной солнечной радиации достигает величины $1350 \mathrm{kBT} \cdot 4 / \mathrm{M}^{2}$, а летом это значение увеличивается более чем в 4,5 раза. Потенциал ветровой энергии приближается к показателю в 700-800 Вт/м²/год при расчетной скорости ветра в течение года на открытых площадках менее $5,5 \mathrm{~m} / \mathrm{c}$ (в горной местности до 9-10 $\mathrm{m} / \mathrm{c})$ [3].

Потенциал ВИЭ может найти применение для энергоснабжения изолированных от энергосистемы населенных пунктов, рекреационных зон, для переработки дикорастущего сырья, что позволит уменьшить себестоимость производимой продукции и объемы потребления органического топлива, снизить негативное влияние энергетики на экологию [3-5]. 
Получение продуктов высокой пищевой ценности из дикорастущего сырья, произрастающего в Байкальском регионе, будет способствовать развитию экономики региона и во многом зависеть от величины и эффективности применения его ресурсного и энергетического потенциала, сформированного на данной территории.

В ходе исследования проведен анализ потенциально возможных для использования источников энергии, выбрано технологическое оборудование для сушки дикорастущего растительного сырья.

Цель исследования: обоснование применимости возобновляемых источников энергии для технологических процессов сушки и переработки дикорастущего растительного сырья в труднодоступных зонах Байкальского региона с целью получения качественных продуктов высокой пищевой ценности.

Задачи исследования: согласование энергетических характеристик возобновляемых источников энергии с техническими характеристиками технологического оборудования.

Объект исследования. Существует большое разнообразие современных методов и технических средств, применяемых в качестве ВИЭ. Проведенный анализ показал, что наиболее применимыми для данной территории являются следующие виды возобновляемых источников энергии: ветроэнергетические установки, установки солнечной энергетики и малые гидроэнергетические установки.

Для переработки и сушки дикоросов современные технологии прибегают к природным, сублимированным, инфрракрасным (ИК), конвективным, индуктивно-кОндуктивным и другим способам, каждый из которых имеет свои плюсы и минусы при сравнении основных системных параметров. Основными задачами переработки и сушки дикорастущего растительного сырья, с целью получения продуктов высокой пищевой ценности, являются:

- максимальное сокращение времени от сбора до переработки;

- выбор эффрективного технологического оборудования;

- определение оптимальных параметров технологического режима;

- сохранение полученной продукции.

Выбор технологического оборудования зависит от механизма сушки реализуемого в данном устройстве, и применимости данного механизма для конкретного вида продукции.
Результаты исследования и их обсуждение. Анализ известных методов сушки показал, что оптимальным с точки зрения энергетической и технологической эфффективности является инфракрасная сушка $[6,7]$.

Выбранный путь ИК сушки по рейтингу соизмерим с другими методами по основным характеристикам, но показывает лучшие результаты по таким параметрам, как: повышенные показатели качества конечного продукта; снижение энергозатрат при испарении влаги; увеличение концентрации сушки материала (в 1,5-2,0 раза) за счет высокой проникающей способности ИКизлучения в глубину материала. Использование для инфракрасной сушки современных источников излучения с лучшими энергетическими характеристиками, например импульсных излучателей, позволяет значительно повысить эффрективность процесса сушки [7].

Применение импульсной инфракрасной обработки и сушки рационально для всего дикорастущего сырья, в том числе кедрового ореха, дикорастущих растений и ягоды [8].

Для получения продуктов высокой пищевой ценности из дикорастущего сырья сушка должна осуществляться в мягких температурных режимах, то есть скорость нагрева не должна превышать даже $1{ }^{\circ} \mathrm{C} / \mathrm{c}$. Значит, техническое устройство сушилок должно обеспечивать систему управления для данного технологического режима [8].

Из выпускаемого в России оборудования наибольший интерес представляют такие устройства, которые способны обеспечить необходимые технологические режимы. На сегодняшний день в России существуют огромный выбор различных сушилок различных типов, конфигураций, моделей. В них используются различные технологии сушки, которые имеет свои особенности и подходят для разных типов сырья.

В таблице представлено описание и характеристики достаточно распространенных на российском рынке сушильных шкафов, основанных на инфракрасно-конвективном методе сушки. Анализ характеристик и особенностей выпускаемых в России сушильных шкафов показал, что установки типа «Универсал-СД-4» в большей степени годятся для сушки дикорастущего растительного сырья (ягод, грибов, трав). Данный сушильный шкаф имеет минимальное энергопотребление, которое может обеспечить микроГЭС, а система управления способна обеспечивать необходимые режимы и 
Вестник КрасТАYУ. 2019. № 11

качество готового продукта. Также данный сушильный шкаф имеет хорошую защиту от перегрузок и перегрева. Кроме того, сушильный шкаф прост в эксплуатации и сопоставим по стоимости с аналогичными установками.

\section{Технические характеристики сушильных шкафов}

\begin{tabular}{|c|c|c|c|c|c|c|c|c|c|}
\hline \multirow[b]{3}{*}{$\begin{array}{c}\text { Типы } \\
\text { шкафовов }\end{array}$} & \multicolumn{9}{|c|}{ Технические параметры } \\
\hline & \multirow{2}{*}{$\begin{array}{c}\text { Номи- } \\
\text { нальное } \\
\text { напря- } \\
\text { жение } \\
\text { питания, } \\
\text { Uном, B }\end{array}$} & \multirow{2}{*}{$\begin{array}{c}\text { Макс. } \\
\text { потреб- } \\
\text { ляемая } \\
\text { мощ- } \\
\text { ность, } \\
\text { P мах, кBт }\end{array}$} & \multirow[b]{2}{*}{$\begin{array}{c}\text { Средняя } \\
\text { мощность, } \\
\text { P }_{c p}, \text { кВт }\end{array}$} & \multirow[b]{2}{*}{$\begin{array}{l}\text { Режим } \\
\text { работы }\end{array}$} & \multirow[b]{2}{*}{$\begin{array}{c}\text { Характе- } \\
\text { ристика } \\
\text { питаю- } \\
\text { щей } \\
\text { сети }\end{array}$} & \multicolumn{4}{|c|}{$\begin{array}{l}\text { Масса продукта } \\
\text { на одну загрузку }\end{array}$} \\
\hline & & & & & & Продукт & $\begin{array}{c}\text { Масса } \\
\text { загруз- } \\
\text { ки, кг }\end{array}$ & $\begin{array}{c}\text { Время } \\
\text { суш- } \\
\text { ки/вяле- } \\
\text { ния, час }\end{array}$ & $\begin{array}{c}\text { Конеч- } \\
\text { ная } \\
\text { влаж- } \\
\text { ность, } \\
\% \\
\end{array}$ \\
\hline \multirow{3}{*}{$\begin{array}{l}\text { Омега- } \\
\text { драйв }\end{array}$} & \multirow{3}{*}{$380 / 220 \mathrm{~B}$} & \multirow{3}{*}{12} & \multirow{3}{*}{$6-9$} & \multirow{3}{*}{$\begin{array}{c}\text { Про- } \\
\text { должи- } \\
\text { тельный }\end{array}$} & \multirow{3}{*}{ 50 Гц } & Грибы & $60-90$ & $4-6$ & 12 \\
\hline & & & & & & Ягоды & $80-120$ & $8-16$ & 12 \\
\hline & & & & & & Травы & $30-35$ & $0,5-1,5$ & 12 \\
\hline \multirow{3}{*}{$\begin{array}{l}\text { Универ- } \\
\text { сал-СД-4 }\end{array}$} & \multirow{3}{*}{$380 / 220 \mathrm{~B}$} & \multirow{3}{*}{10} & \multirow{3}{*}{$3-6$} & \multirow{3}{*}{$\begin{array}{c}\text { Про- } \\
\text { должи- } \\
\text { тельный }\end{array}$} & \multirow{3}{*}{ 50 Гц } & Грибы & $50-90$ & $4-6$ & 12 \\
\hline & & & & & & Ягоды & $60-120$ & $8-16$ & 12 \\
\hline & & & & & & Травы & 30 & $0,5-1,5$ & 12 \\
\hline \multirow{3}{*}{ Сибиряк } & \multirow{3}{*}{$380 / 220 \mathrm{~B}$} & \multirow{3}{*}{13} & \multirow{3}{*}{$7-9$} & \multirow{3}{*}{$\begin{array}{c}\text { Про- } \\
\text { должи- } \\
\text { тельный }\end{array}$} & \multirow{3}{*}{ 50 Гц } & Грибы & 50 & $4-5$ & 12 \\
\hline & & & & & & Ягоды & 50 & $4-6$ & 12 \\
\hline & & & & & & Травы & 50 & 30 мин & 12 \\
\hline
\end{tabular}

Рассматриваемое оборудование для сушки дикоросов использует ИК-конвективный метод, благодаря которому появляется возможность извлекать влагу из сырья путем теплового нагрева (при этом необходимо применять заданный диапазон ИК излучения) и обязательно удалять её из камеры путем конвекции воздуха. Внутри сушильного шкафа вмонтированы трубчатые элементы нагрева, покрытые специальной керамикой, размещенные в один ряд попарною. В такой сушилке удобно производить сушку дикорастущего сырья: грибов, ягод, лекарст- венных трав и т. п. Система управления позволяет поддерживать температуру в сушильной камере в пределах заданного значения, не допуская перегрева продукта.

Для подтверждения заявленных производителем параметров был произведен эксперимент по сушке кипрея узколистного на установке «Универсал СД-4» (рис. 2). Эксперимент проводился в лаборатории «Энергосбережения в электротехнологиях» Иркутского ГАУ в начале июля 2019 г.
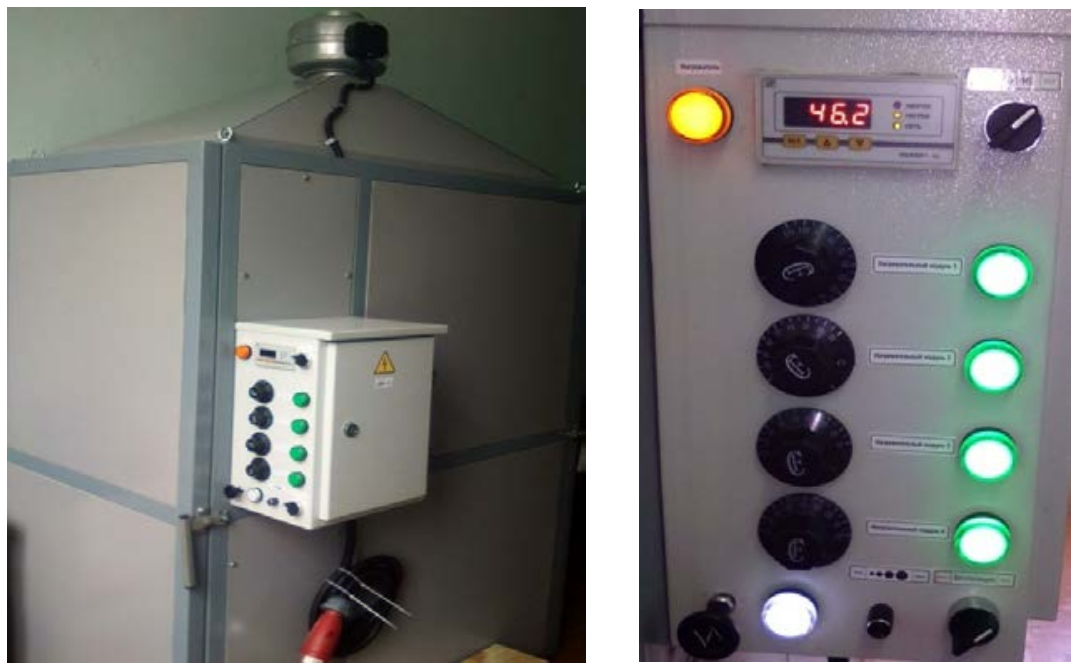

Pис. 2. Сушильный шкафр «Универсал СД-4» в работе 
Соблюдая биотехнические условия нагрева, с целью сохранения ценных питательных свойств, кипрей узколистный следует сушить при температурах, не превышающих $50^{\circ} \mathrm{C}$. Установленные параметры позволяет поддерживать система управления данного устройства, а результаты проведенных экспериментов представлены на рисунке 3 .

Проведенный эксперимент, а также анализ характеристик и особенностей выпускаемых сушильных шкафов подтвердил, что для сушки дикорастущего растительного сырья шкаф
«Универсал-СД-4» может поддерживать необходимый температурный режим при небольшой потребляемой мощности.

Анализ графрика на рисунке 3 показывает, что для достижения предельно допустимой температуры биотехнических условий нагрева необходимо и достаточно мощности 5 кВт. Для дальнейшего удаления связанной влаги мощность необходимо снижать. Данную мощность способен обеспечить возобновляемый источник энергии, что позволит получать продукты высокой пищевой ценности.

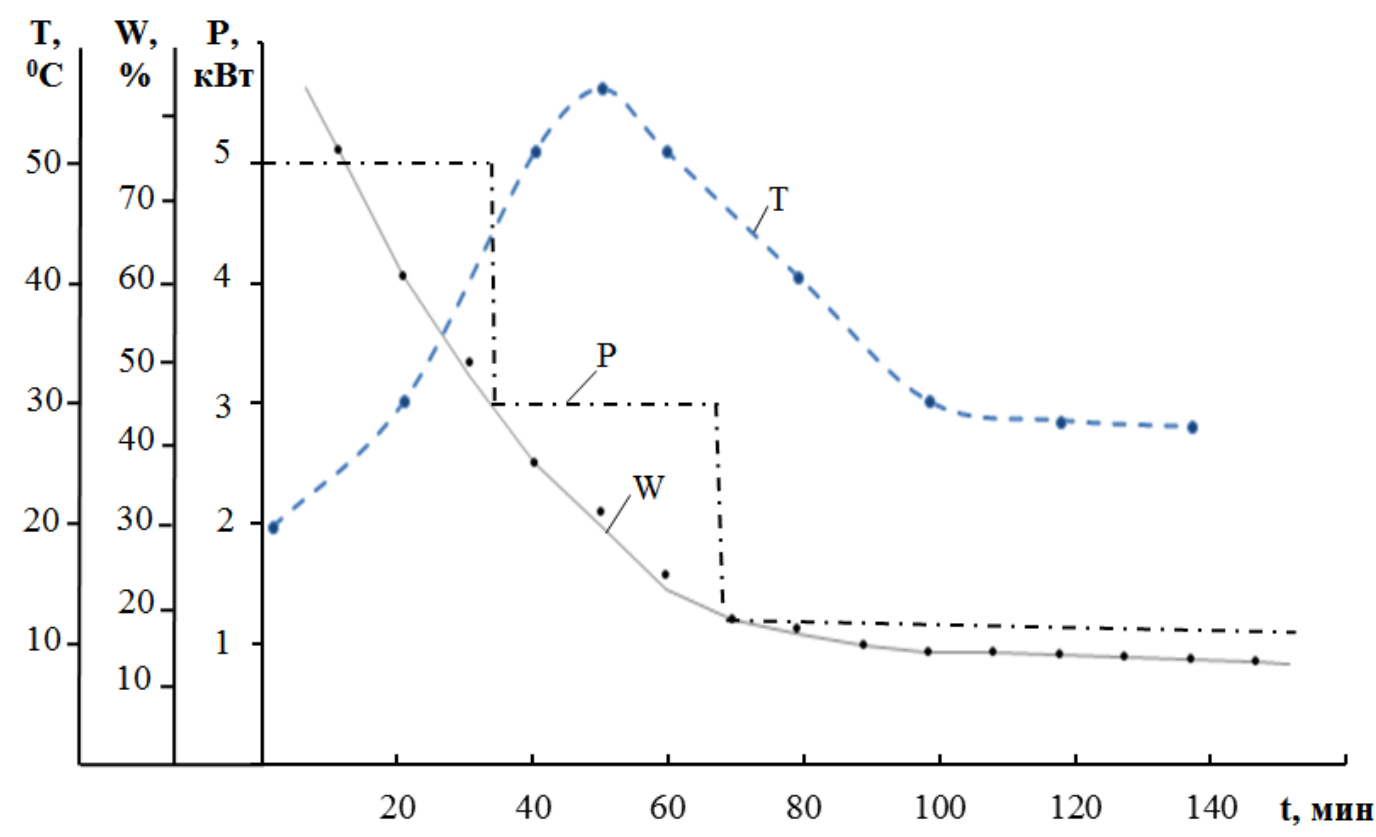

Puc. 3. График зависимости температуры, влажности сырья и мощности от продолжительности обработки

Выводы. Применения ВИЭ для обеспечения энергии установок сушки дикорастущего растительного сырья является перспективным направлением для получения продукции высокой пищевой ценности. Использование для данных целей сушильного шкафа «Универсал СД-4» позволяет поддерживать необходимый режим сушки при малых мощностях, выполнять биотехнические условия нагрева сырья и получать продукты высокой пищевой ценности. Мощности источника энергии 5 кВт достаточно для выполнения биотехнических условий нагрева и сушки дикорастущего растительного сырья.

\section{Литература}

1. Потенциальные запасы дикорастущих ресурсов Иркутской области / Я.М. Иваньо [и др.]; под ред. Я.М. Иваньо. - Иркутск: Издво Иркутского ГАУ, 2017. - 156 с.

2. Актуальные проблемы экологической безопасности южных регионов Восточной Сибири / А.Н. Петров, Т.И. Морозова, А.Г. Еникеев, Е.А. Матосова // Изв. ИГЭА. - 2012. № 5. - C. 204-208.

3. Иванова И.Ю., Тугузова Т.Ф., Симоненко А.Н. Эффрективные направления развития малой энергетики на востоке России // 
Энергетическая политика. - 2009. - Вып. 2. - C. 45-52.

4. Иванова И.Ю., Попов С.П., Тугузова Т.Ф. Эффрективность и масштабы использования возобновляемых источников энергии для изолированных потребителей // Изв. РАН. Энергетика. - 2006. - № 3. - С. 110 114.

5. Ушаков В.Я. Современная и перспективная энергетика / Том. политехн. ун-та. - Томск, 2008. - 468 c.

6. Применение импульсного инфракрасного излучения в технологии сушки сырья растительного и животного происхождения / И.В. Алтухов, И.В. Буянова, Н.В. Цугленок [и др.] // Foods and Raw materials. - 2019. № 1. - C. $151-160$.

7. Алтухов И.В., Цугленок Н.В. Импульсные излучатели для сушки растительного сырья // Актуальные вопросы аграрной науки. 2018. - № 27. - C. 5-12.

8. Altuhov I., Shamarova N., Suslov K., Gerasimov D., Shushpanov I., Lombardi P., Komarnicki P. Stabilizing the control of a plant material drying process in off-grid power systems (2019) Proceedings of the 10th International Scientific Symposium on Electrical Power Engineering, Elektroenergetika 2019, pp. 363-367.

\section{Literature}

1. Potencial'nye zapasy dikorastuschih resursov Irkutskoj oblasti / Ya.M. Ivan'o [i dr.]; pod red. Ya.M. Ivan'o. - Irkutsk: Izd-vo Irkutskogo GAU, 2017. - 156 s.
2. Aktual'nye problemy ekologicheskoj bezopasnosti yuzhnyh regionov Vostochnoj Sibiri / A.N. Petrov, T.I. Morozova, A.G. Enikeev, E.A. Matosova // Izv. IGEA. - 2012. № 5. - S. 204-208.

3. Ivanova I.Yu., Tuguzova T.F., Simonenko A.N. Effektivnye napravleniya razvitiya maloj energetiki na vostoke Rossii // Energeticheskaya politika. - 2009. - Vyp. 2. S. 45-52.

4. Ivanova I.Yu., Popov S.P., Tuguzova T.F. Effektivnost' i masshtaby ispol'zovaniya vozobnovlyaemyh istochnikov energii dlya izolirovannyh potrebitelej // IzV. RAN. Energetika. - 2006. - № 3. - S. 110-114.

5. Ushakov V.Ya. Sovremennaya i perspektivnaya energetika / Tom. politekhn. un-ta. - Tomsk, 2008. - $468 \mathrm{~s}$.

6. Primenenie impul'snogo infrakrasnogo izlucheniya $v$ tekhnologii sushki syr'ya rastitel'nogo i zhivotnogo proiskhozhdeniya I I.V. Altuhov, I.V. Buyanova, N.V. Cuglenok [I dr.] // Foods and Raw materials. - 2019. № 1. - S. $151-160$.

7. Altuhov I.V., Cuglenok N.V. Impul'snye izluchateli dlya sushki rastitel'nogo syr'ya // Aktual'nye voprosy agrarnoj nauki. - 2018. № 27. - S. 5-12.

8. Altuhov I., Shamarova N., Suslov K., Gerasimov D., Shushpanov I., Lombardi P., Komarnicki $P$. Stabilizing the control of a plant material drying process in off-grid power systems (2019) Proceedings of the 10th International Scientific Symposium on Electrical Power Engineering, Elektroenergetika 2019, pp. 363-367. 